\title{
Enhancing ICT Culture in Nigeria for National Development - The Role of Smartphones
}

\author{
Ogwuegbu, David Azunna \\ Department of Computer Science \\ Federal College of Education (Special), Oyo, Nigeria
}

\author{
Doi:10.5901/mjss.2014.v5n26p144
}

\begin{abstract}
This paper discusses how the information and communication technology culture in Nigeria could be enhanced through the use of smartphones. The concept of what smartphones represent in the context of this paper was specified. ICT culture as regards to its usage and adoption was considered with some focus on mobile communications. The propensity that smartphones have of transforming a nation economically and otherwise was examined under portability, convergence and versatility, and web access. Recommendations were then made towards harnessing smartphones for national development.
\end{abstract}

Keywords: Smartphones, ICT culture, national development, technological advancement, information age.

\section{Introduction}

Technological advancement could be regarded to be an ancient practice in man. Man, being an intelligent and social creature desires a better way of life. This desire, coupled with consistent, diligent efforts has brought about stages of technological development in human history, the latest being the information era.

In this information age, technology (specifically, information and communication technology (ICT) has enabled the transformation of the world into a global village. Vast amount of simple and complex data are now transmitted from one location to another at unprecedented speed and accuracy. In addition, globalisation could be said to have been boosted through ICT-enabled activities.

The embrace of information and communication technology brings about an added way of life. Thus, ICT culture can be regarded as the way in which ICT objects affects the lives of people in a society. The ICT objects include electronic text; audio, visual and video materials. The ways in which these objects influence daily activities of people within a society contributes to the rate and extent of human development in that society.

Smartphones represent part of the innovations in the ICT industry. This paper examines the role smartphones play in enhancing the ICT culture in Nigeria.

\section{What are Smartphones?}

A smartphone is a handheld device that combines mobile phone capabilities with the more basic features that are found in a handheld computer or a personal digital assistant (Beal, 2014).

There is no standard industry definition that can be used in declaring that a mobile device is a smartphone (Cassavoy, 2014). Due to technological advancements, attributes for which a mobile device is traditionally known could be seen in another device (Beal, 2008). However, the basic characteristics that were given by Cassavoy (2014) would be used in this paper to differentiate between a smartphone and other handheld devices. The features are given below:

Operating system. A smartphone is expected to have an operating system that will enable it to run applications. Examples include the iOS, BlackBerry OS, Google's Android OS, etc.

Applications: Although almost all mobile phones these days have some kind of software, a smartphone will have the capability to handle more complex ones. It could support the downloading of applications. Smartphone applications may be used to create and edit Microsoft Office files, handle personal and business finance management, get driving directions through Global positioning Systems (GPS), etc.

Web Access: A good number of smartphones can access the Web at high speeds due to the development of $4 \mathrm{G}$ and $3 G$ data networks, as well as the addition of Wi-Fi support to many handsets. Although not all smartphones offer high-speed Web access, they all at least provide some sort of access. 
QWERTY Keyboard: A smartphone possesses a QWERTY keyboard. The keyboard layout is such as is obtained in a typical computer keyboard as opposed to the numeric keypad arrangement where, for instance the number 1 would have to be tapped to enter letter A, B, or C. The keyboard may be offered in the form of software or hardware.

Messaging: Smartphones not only send and receive text messages, but also handle e-mail. A smartphone can synchronize with a personal and, presumably a professional e-mail account. Some smartphones can accommodate the use of more than one e-mail account. Others enable access to the popular instant messaging services like Yahoo! Messenger

\section{ICT Culture in Nigeria}

Information and communication technology devices have become valuable tools for aiding in accomplishing day-to-day personal and professional tasks satisfactorily. Since man does not live in isolation and at one time or the other finds himself passing on information or engaging in communication, ICT regularly becomes imperative. According to Rouhana (2011), ICT has become a major vehicle for enriching our "creative capital" that underpins our societal vitality, our economic growth and ability to compete on a global scale. Information and communications technology is a dominant and pervasive element of modern life (The Conference Board, 2011). Also, globalization and its driver the new ICTs have taken the world by storm and their message of change or be damned is being trumpeted loudly from a multiplicity of podiums by a growing band of important personalities and organisations (Etta \& Parvyn, 2003).

The Nigerian society has experienced technological transformation. Despite this, products of various developmental stages of ICT may not be said to have gone into extinction in Nigeria. Infact, Aziken and Emeni (2010) posited that although the traditional systems of communication may be old and different in their principles from the new ones, they remain what basically sustain the information demands of the rural population. This notwithstanding, modern ICTs like the Internet, satellite television network, and mobile telephony have been embraced in Nigeria. They could be said to be in use both in the rural and urban settlements with greater patronage at the developed areas.

Achimugu, Oluwagbemi, Oluwaranti, \& Afolabi (2009) stated that in developing countries, information technology has not been effectively adopted by many micro-enterprises, agroindustries, small traders, farming/livestock households, public offices, schools, health centres, etc., particularly in the rural areas. They asserted that the Internet has become a vital tool for business growth, social activities and research in Nigeria, but that the country is said to be attempting giant strides in embracing its usefulness and applications.

Of particular interest in this paper is the issue of mobile means of communication. From the advent of Global Systems for Mobile Communications (GSM) operations in Nigeria in August, 2001 (Jidaw Systems, 2013; Sulaiman, 2010), mobile communications is observed to have grown tremendously. With information gathered in 2012 of 112 , 780,000 mobile telephone subscribers, Nigeria is ranked $10^{\text {th }}$ in the world by Central Intelligence Agency (2014) with respect to teledensity with subscribership base close to 60 per 100 persons. Although the growth of mobile telephony in Nigeria is impressive, of importance is the quality of the phones in use, which will contribute to the kind of services they will render as well as their usage towards national development.

\section{Smartphones and Nigeria ICT Culture Enhancement for National Development}

The mechanism of economic growth and development is knowledge, not physical goods or natural resources in an economics that is rooted in knowledge networks (Seki, 2008). ICT provides the basis for the networks.

Among the three strings of technological advance (materials, biotechnology, and information), information technology is much more powerful than the others in deciding the magnitude and quality of economic production (Achimugu, Oluwagbemi, Oluwaranti, \& Afolabi (2009). In addition, Ohiagu (2010) opines that the Internet and cable television networks are believed to be the most influential of all Information and Communication Technologies (ICTs) in modern digital society. However, with the capability and characteristics of smartphones, they (the smartphones) could be said to have an essential role in transforming a nation economically and otherwise due to the following reasons:

- Portability: Smartphones, being mobile phones are portable hence; they can be carried about by the user. Thus, with them messages of various kinds can be received speedily and conversations from far and near, including conference calls can take place at any time of the day with less consideration to the location of the user. In addition, Achimugu, Oluwagbemi, Oluwaranti, \& Afolabi (2009), asserted that an increase in information content has significantly changed the concept of production, signifying the importance of timely information flows. Smartphones offer timely flow of information since they enable the receipt of messages (including electronic mails) anytime, anywhere due to their portable nature. 
- Convergence and Versatility: A smartphone is basically a meeting point for various ICT capabilities. With the available hardware and support from a variety of software, we see a single device performing assorted functions. Apart from the built-in applications, a variety of other applications can be installed and run on them. Generally, the built-in and downloadable applications include but are not limited to the following: cellular phone calls and contact list, texting, web browser, e-mail app, weather, alarm clock, stopwatch, timer, calculator, calendar, music player, photo album, camera (still and video), GPS navigation, flashlight, dictionaries, encyclopedias, news, stock markets, video calling (Skype, Tango, etc.), games and entertainment, e-book reader, converters (money, measurements), Internet radio (Pandora, etc.), YouTube viewer, voice recorder, and compass. ("smartphone features", 2014).

- Web Access: It is considered necessary that the issue of web access on smartphones be discussed separately as this is perhaps the most beneficial added capability of a smartphone - combining the ability to use a phone with access to the Internet. By observation, most ICT users in Nigeria do not require a personal computer in form of a desktop or laptop with Internet access for their daily activities, neither can they afford (even if they have it installed) to watch satellite television network for hours daily to keep abreast with important issues globally. However, it may be considered necessary that a means exists through which they can quickly receive vital information or communicate both locally and possibly, internationally. Smartphones could be said to fit into satisfying this demand.

\section{Recommendations}

The beauty of smartphone usage is enhanced when the fraction of the population using it increases. The benefits are further boosted when they are used for economic/developmental gains. Therefore, the following recommendations are made as given below:

- Educational Use: If an idea is to be introduced, one of the best channels to do so is through the academic institutions, a reason being that the students are the future of the nation and any culture imbibed into them could have widespread and long-lasting effects. It is believed that mobile phones are already being used by students, particularly those in tertiary institutions for academic research. The various ICT capabilities of smartphones should be harnessed for educational benefits. Hence, the intensity of smartphones for academic activities across the strata of educational institutions (primary, secondary and tertiary) is advocated. For instance, the culture of communication among members of staff and most importantly between teachers and students through text messages and electronic mails should be promoted. Teachers should give assignments that will provoke the students to go to the web for information and possibly, collaboration. The smartphones should be able to help the students access the information passed, initiate and perhaps complete the required educational activity. If they cannot be used to carry out the assignment completely, they would have been a springboard for initiating the task. An ICT-enabled educational culture is favourable for national development, and smartphones due to the convergent and versatile properties they possess are seen to be good tools for such civilization.

- Economic integration: Smartphones should permeate into the economic activities of Nigerians. The farmers, traders, artisans, and citizens in other professions and vocations should employ them for their various activities. For instance, farmers and traders could receive information and/or get engaged in both local and international transactions regarding their products through text messages, electronic mails, voice and video calls, etc.

- Training: There is the need for training of the citizenry on the benefits of the use of smartphones for both personal and professional tasks. This training could be conducted by or through channels like the professional and vocational bodies, educational institutions, agents of government, religious organisations, and nongovernmental agencies. A situation where a large number of persons cannot receive the training simultaneously, the train-the-trainers approach could be adopted where few persons will be trained who would in turn deliver the skills acquired to others. The trainings should be conducted periodically bearing in mind the dynamic nature of the ICT industry.

- Acquisition: It is obvious that smartphones will be higher in price than the conventional phones. Thus, there is the need for a system where they can be acquired by the target users with less convenience. An example is a method where the cost of purchase will be spread over a period of time with part payment being made regularly and periodically until payment is completed. 
- Availability of Infrastructure: The availability of ICT infrastructure is a factor that cannot be ignored if ICT culture is to be upgraded through smartphones. Steady progress in the provision of the needed infrastructure by all stakeholders is desired and advocated.

\section{Conclusion}

In the interest of trying to make information available in the right form to the right user both at the personal and organizational levels, and at the right time, the attempt to cope with great flood of information has led to the need for a more sophisticated approach of handling information faster and better (Ogbomo \& Ogbomo, 2008). Economic globalisation and the new Information and Communication Technologies are seen as the engines of contemporary global economy driving a new information world order in which most of the continent of Africa is not faring too well (Etta \& Parvyn, 2003). In this information age, Nigeria as a nation cannot afford to lag behind, but rather should rise up towards utilizing the technological concept that smartphones convey for national development. The time to do so is now.

\section{References}

Achimugu, P., Oluwagbemi, O., Oluwaranti, A., \& Afolabi, B. (2009). Adoption of information and communication technologies in developing countries: An impact analysis. Journal of Information Technology Impact, 9(1), 37-46. Retrieved October 3, 2014 from http://www.jiti.com/v09/jiti.v9n1.037-046.pdf

Aziken, L. C. \& Emeni, C. A. (2010, December). Traditional systems of communication in Nigeria: a review for improvement. Knowledge Review, 21 (4), 23-29. Retrieved October 03, 2014 from http://www.globalacademicgroup.com/journals/knowledge\%20review /traditional\%20systems\%20of\%20communication\%20in\%20nigeria.pdf

Beal, V. (2008). The difference between a cell phone, smartphone and PDA. Retrieved September 30, 2014 from http://www.webopedia.com/DidYouKnow/Hardware_Software/smartphone_cellphone_pda.asp

Beal, V. (2014). Smartphone. Retrieved on September 30, 2014 from http://www.webopedia.com/TERM/S/smartphone.html

Cassavoy, L. (2014). What makes a smartphone smart? Retrieved on September 30, 2014 from http://cellphones.about.com/od /smartphonebasics/a/what_is_smart.htm

Central Intelligence Agency (2014). The world factbook. Retrieved October 3, 2014 from https://www.cia.gov/library/publications/theworld-factbook/geos/ni.html

Etta, F.E. \& Parvyn-Wamahiu, S. (Eds.) (2003). Information and communication technologies for development in Africa, Volume 2: The experience with community telecentres. Retrieved October 3, 2014 from http://books.google.com.ng/books?id=UQchmbS9dQIC \&pg=PA188\&lpg=PA188\&dq=Crede,+A.,+\%26+Mansell,+R.+\%281998\%29.+Knowledge+societies.+in+a+nutshell:+Information+t echnologies+for+sustainable+development.\&source=bl\&ots=XOBM3On7Q3\&sig=imLmRlqqhDcOiO20jyhsvuvSmWY\&hl=en\&sa =X\&ei=9ZwuVJytN4eoyQTVh4LIBQ\&ved=0CDAQ6AEwAw\#v=onepage\&q=Crede\%2C\%20A.\%2C\%20\%26\%20Mansell\%2C\%2 OR.\%20\%281998\%29.\%20Knowledge\%20societies.\%20in\%20a\%20nutshell\%3A\%20Information\%20technologies\%20for\%20su stainable\%20development.\&f=false

Jidaw Systems (2013). ICT in Nigeria. Retrieved October 3, 2013 from http://www.jidaw.com/category/ICT_Nigeria

Ogbomo, M.O. \& Ogbomo, E.F. (2008). Importance of information and communication technologies (ICTs) in making a healthy information society: A case study of Ethiope East Local Government Area of Delta State, Nigeria. Library Philosophy and Practice. Retrieved October 3, 2014 from http://www.webpages.uidaho.edu/ mbolin/ogbomo2.pdf

Rouhana, K. (2011, July). ICT and cultural heritage: research, innovation and policy. ERCIM News, 86, 3. Retrieved October 3, 2014 from http://ercim-news.ercim.eu/images/stories/EN86/EN86-web.pdf

Seki, I. (2008). The importance of ICT for the knowledge economy: A total factor productivity analysis for selected OECD countries. In Esen, O. \& Ogus, A. (eds.) Proceedings of the International Conference on Emerging Economic Issues in a Globalizing World, Proceedings of the IUE-SUNY Cortland Conference in Economics, Izmir University of Economics. Retrieved October 3, 2014 from http://eco.ieu.edu.tr/wp-content/proceedings/2008/0804.pdf

Smartphone features (2014). In PC: Encyclopedia. Retrieved October 3, 2014 from http://www.pcmag.com/encyclopedia /term/64233/smartphone-features

Sulaiman, S. (2010). The state of ICT in Nigeria and its economic implications. Retrieved October 3, 2014 from https://www.scribd.com/doc/31835015/The-State-of-ICT-in-Nigeria

The Conference Board (2011). Executive summary - The linked world: How ICT is transforming societies, cultures, and economies. Retrieved October 4, 2014 from http://www.fi3p.eu/assets/pdf/Executive-Summary-Final.pdf 